\title{
The Influence of Perceived Risk on the uptake of Mobile Money Services by SMEs Operations in Karagwe District, Tanzania
}

\author{
${ }^{1} \mathrm{PhD}$ Student - The Open University of Tanzania \\ ${ }^{2}$ Lecturer - The Open University of Tanzania \\ ${ }^{3}$ Chief Executive Office - Watumishi Housing Company
}

Elizeus Kalugendo John ${ }^{1}$, Raphael Gwahula ${ }^{2}$, Fred M. Msemwa ${ }^{3}$

\begin{abstract}
Mobile money services (MMS) usage through mobile phones and other ICT tools has increased with time and dramatically pave the way in business communication among Small and Medium Enterprises (SMEs) in Tanzania. Some of SME operators in Karagwe District are escaping from MMS usage due to perceived risk associated with financial communication and hence pulls down its usage. The growth of MMS and perceived risk embodied in it is taking a crucial part in business communication. A study sought to analyse the influences of perceived risk on MMS usage to support SME business undertaking. Perceived risk theory was reviewed and become a corners stone for this study. It can be recalled that, risk is the stake in use and individual feeling which is subjected in certainty. Variables in mobile MMS usage including financial risk, performance risk and SME business operation were identified and measured using quantitative techniques. Questionnaires were designed to collect data from all respondent. Data were collected from 154 runners of micro, small and medium enterprises using simple random sampling method. Data were analysed by sing SPSS version 22 in which descriptive analysis were used to analyses demographic data while factor analysis were used to test the study hypothesis. The study found that financial and operational risks are negatively and significantly influences MMS usage in business operation. This study highlights remedial action for players of MMS in business operation which will facilitate to mitigate perceived risk and enhance smooth running SME business orientation. Furthermore, the study recommends that the Government should institute the developed ICT policies and other legislation to enforce MMS usage security and regulate its uptakes.
\end{abstract}

Keywords- Perceived Risk, Mobile Money Services, SMEs operations.

www.ijaems.com

\section{INTRODUCTION}

1.1. Background of the study

Karagwe is found on the north-west of Tanzania being bordered with two countries namely Rwanda and Uganda. Its geographical position and socio-economic context influences the commencement of the business and particularly the Small and Medium Enterprises (SMEs) in order to improve their living standards(Gonzales, 2012; Mohamad, et al., 2017). Nowadays, Mobile Money Services (MMS) usage has become key driver in business communication in the developing countries which offers consumers (both merchant and buyers) a reliable financial communication channel and other information related benefits which influence its usage(Maditinos,et al., 2013). MMS usage will bring business competitiveness by changing industrial structure, giving SMEs the way to outperform their rivals and spawns whole new businesses operations(Mutalemwa \& Anthony, 2014; Baganzi \& Lau, 2017). Other benefits on MMS usage includes the control of accounts and perform financial transaction at any time provided there is network connectivity. MMS usage is considered to enhance customer satisfaction by delivering faster and easier services through electronic platform(Kalugendo, et al., 2018; Buhalis, 2013).

Karagwe district has experienced unstable mobile network crossing to all localities due to infrastructure bottleneck. The mobile network failure to some localities forces the user of MMS to travel to a distance in order to trace the network and hence perform financial and non-financial communication. Disregarding of several advantage of MMS usage, there are good number of SMEs operators still refusing using the services due to risk and other emanating factor embodied on it. It was not clear if the challenges associated with MMS usage to communicate business information related to financial risk, performance risk and privacy risk are the influencing factors in its uptake. 
1.2. Objectives

1.2.1. General Objective

The main objective of the study is to investigated the Influence of Perceived Risk on the uptake of Mobile Money Services by SMEs Operations in Tanzania

\subsubsection{Specific Objective}

Specific objectives of the study are:

i. To assess the influence of financial risk on mobile money services usage by SMEs Operations.

ii. To examine the influence of performance risk on mobile money services usage by SMEs Operations.

iii. To examine the influence of privacy risk on mobile money services usage by SME Operations.

\section{LITERATURE REVIEW}

\subsection{Theoretical Literature Review}

The concept of risk is organized around the idea that consumer behavior involves risk in the sense that any consumer action will produce consequences that they cannot anticipate with anything approaching certainty(Maziriri \& Chuchu, 2017). Perceived risk theory proposed that, consumer behavior involves risk in the sense that any action of a consumer will produce consequences that he cannot anticipate with anything approximating certainty, some of which at least are likely to be unpleasant(Li \& Bai, 2010). Perceived risk theory (PRT) is powerful model in explaining a consumer's behavior due to the fact that because consumers are more often motivated to avoid mistakes than to maximize utility in purchasing(Kallamarthodi \& Vaithiyanathan, 2011). PRT was described by looking at the nature and amount of risk contemplating a particular decision (Cox and Rich, 1964; Chang and $\mathrm{Wu}, 2012$ ). It should be noted that perceived risk is not only related to consumers pre-decision information acquisition and processing activity but also to post-decision processes as well (Ngaruiya, et al., 2014) . Concerning mobile money service, the perceived risk is defined as the extent of which an enterprise operators subjectively belief about the potential losses caused by uncertainties of using mobile money technology.

\subsection{Empirical Literature Review}

Various empirical studies identify perceived risk as having a significant negative and direct effect on mobile money services usage that allows small and more frequent of money transfer in mitigating risks embodied in business operations. For instance, Lee (2009) investigated five types of risk in studying Internet banking adoption, including performance, social, time, financial and security risk. Featherman \& Pavlou (2003) adopted performance, financial, time, psychological, social, privacy and overall risk as the key facets of perceived risk to predict the eservices usage.

Bagana \& Muturi, (2015) conducted a study on factors affecting the uptake of MMT services by Micro and Small Enterprises in Pokot Central Sub-County. It was found that although the risk of sending money to the wrong telephone number is real, the same has not discouraged uptake of MMT service whereby the information on the transfer made can be retrieved and the money received back. Aldhmour (2016) argued that, the degrees of risk that the consumers perceive and their ability to tolerate it are regarded as attitudinal factors that affect their technology use behaviors. It is hence vivid to conduct a study in order to come up with the factors that hinder the perceived risk in the uptake of mobile money services for SMEs operation taking on board the contextual is sue and methodological aspects.

\section{CONCEPTUAL FRAMEWORK AND RESEARCH HYPOTHES IS}

\subsection{Conceptual Framework}

The present study focuses on exploring the determinants of perceived risk on Mobile Money Services (MMS) usage, adopting the Perceived Risk theory (PRT) as the most widespread, appropriate and useful path of examination (Mohammed, et al., 2013). The conceptual framework has been based on the synthesis of various previous studies related on perceived risk on technological usage to support business operations (Bagana and Muturi, 2015; Maditinos, et al., 2013). In this context therefore, the conceptual framework aligned the influencing factors on mobile money services usage as financial risk, privacy risk and performance risk has an influence on the uptake of MMS usage to support business operation as per Figure 1. 


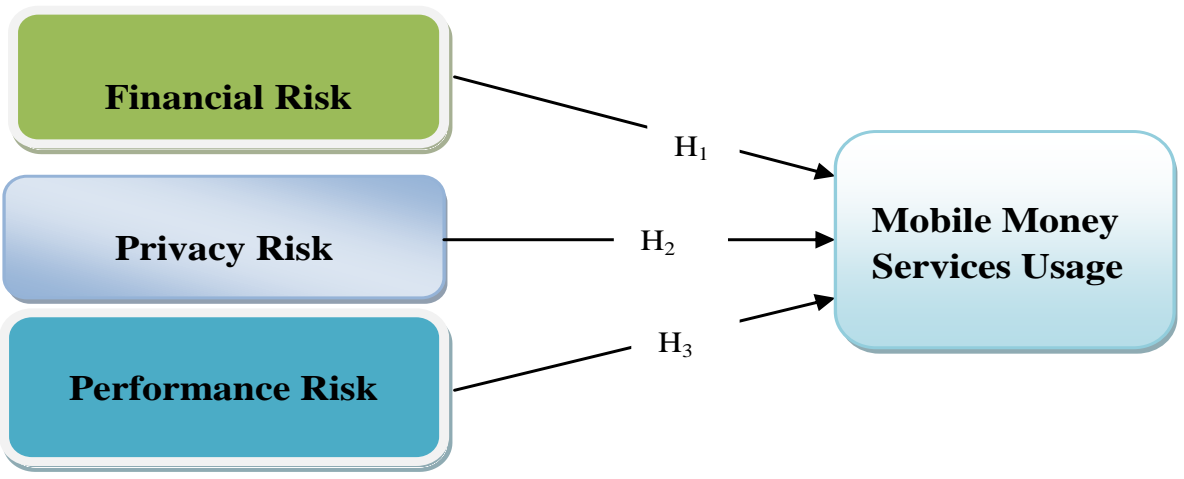

Fig.1: Conceptual Framework (Study determinants)

Source: Developed by Authors from Literature Review (2018)

\subsection{Research Hypothesis}

3.2. 1. Financial Risk: Most of SME business runners fear to use MMS due to financial loss that may occur during performing financial transactions. Financial risk may results from network failure, transactions attacks and unauthorized accounts access through false identification (Akın and Seçilmiş, 2015; Maditinos, et al., 2013). The typical safeguards of conventional traditional documentation are not present in the MMS usage environment and, thus, feelings of insecurity and uncertainty may be generated. Therefore, the following hypothesis is examined:

$H_{l}$ : Financial risk has negative and significant influencing on the uptake of mobile money services

\subsection{Performance Risk: Network failure during} executing financial transaction may lead to loss of financial data and hence had an impact on executing financial transactions via MMS. This attempt cause risk of losing wealth and may ultimately impede business operations. Empirical evidence illuminated that Performance Risk is crucial and play an important role in understanding the significance influence on mobile money services usage to support SME business operation (Ali et al., 2011; Kolesova, 2018; Lake, 2013). Therefore, the following hypothesis is examined:

$\mathrm{H}_{2}$ : Performance risk has negative and significant influence on the uptake of mobile money services

3.2. 3. Privacy Risk: Privacy risk involves the possible loss caused by private information of consumer individuals exposed in mobile money services usage. Some consumer feels that they are in a vulnerable position because they have no control over transaction made and over their financial prospects which may put their as sets at risk(Liu, et al., 2012).
$H_{3}$ : Privacy risk has negative and significant influence on the uptake of mobile money services

\section{METHODOLOGY}

The study used positivism philosophy in order to collect data about the study objective and search for causal relationship while knowledge on the usage of mobile money services was developed through objective measurement. Therefore, this study was empirical and systematic, preferring precise quantitative approach to test the cause and effect and assess the significant of each parameter in the model relating to perceived risk on mobile money services by SMEs in Karagwe district. Explanatory crosssection survey was used to describe, explore and analyze the relationship between variable in the model given larger geographical scattered objectives. Stratified sampling techniques were used to stratify sample on 22 wards in Karagwe namely, 18 being rural wards and four (4) mixed wards. After satisfied sampling techniques, simple random sampling was used to select respondents from each ward in order to avoid biasness. Data were collected from 154 respondents found on their business premises by using survey questionnaires. After data being collected, reliability test were done in which internal consistency across to 26 items yield the Cronbach's Alpha of 0.916 as per Table 1 . In ensuring nomological validity, all standardized coefficient had a significant value greater than 0.2 . This indicates that, data collected were reliable and valid for further analysis.

Table.1: Reliability Statistics

\begin{tabular}{|c|c|c|}
\hline $\begin{array}{c}\text { Cronbach's } \\
\text { Alpha }\end{array}$ & $\begin{array}{c}\text { Cronbach's Alpha Based on } \\
\text { Standardized Items }\end{array}$ & $\begin{array}{c}\text { Number of } \\
\text { Items }\end{array}$ \\
\hline 0.916 & 0.902 & 26 \\
\hline
\end{tabular}

Source: Survey Data (2018) 
Both exploratory and confirmatory analysis was done to examine the inter-correlation between variables and asses the fitting of underlying constructs under each indicator variable respectively. Furthermore, Structural Equation Modeling was used in testing hypothesis and examines the significant effect of each variable.

\section{PRESENTATION OF THE FINDING}

5.1. Factor Analysis

5.1.1. Exploratory Factor Analysis
In performing exploratory analysis, principal axis factor analysis with varimax rotation analysis was done to assess the underlying structure of perceived risk on mobile money services usage by SME operation based on the survey questionnaires. The use of combination of more than one factor extraction shows that, all four constructs in the model yields engine value for correlation matrix greater than 1 in the model and met the Kaiser's criterion which leads to retain only factors with confidence interval greater than one as per Table 2

Table.2: Rotated Component Matrix ${ }^{a}$

\begin{tabular}{|c|c|c|c|c|}
\hline Item & $\begin{array}{c}\begin{array}{c}\text { Financial } \\
\text { Risk }\end{array} \\
\end{array}$ & $\begin{array}{c}\text { Performance } \\
\text { Risk }\end{array}$ & $\begin{array}{c}\text { Privacy } \\
\text { Risk }\end{array}$ & $\begin{array}{l}\text { Mobile Money } \\
\text { Service Usage }\end{array}$ \\
\hline FIR5 & .799 & & & \\
\hline FIR2 & .775 & & & \\
\hline FIR4 & .769 & & & \\
\hline FIR9 & .723 & & & \\
\hline FIR1 & .663 & & & \\
\hline FIR7 & .593 & & & \\
\hline FIR8 & .462 & & & \\
\hline PER1 & & .793 & & \\
\hline PER4 & & .743 & & \\
\hline PER7 & & .728 & & \\
\hline PER6 & & .722 & & \\
\hline PER5 & & .705 & & \\
\hline PER3 & & .518 & & \\
\hline PER2 & & .424 & & \\
\hline PRR3 & & & .784 & \\
\hline PRR5 & & & .784 & \\
\hline PRR1 & & & .771 & \\
\hline PRR8 & & & .597 & \\
\hline PRR4 & & & .509 & \\
\hline PRR6 & & & .481 & \\
\hline PRR9 & & & .454 & \\
\hline PRR7 & & & .434 & \\
\hline MMS2 & & & & .713 \\
\hline MMS4 & & & & .678 \\
\hline MMS1 & & & & .659 \\
\hline Eigenvalues & 7.971 & 2.929 & 2.825 & 1.677 \\
\hline Variance (\%) & 33.213 & 10.486 & 7.970 & 6.668 \\
\hline $\begin{array}{l}\text { Cumulative } \\
\text { Variance (\%) }\end{array}$ & 33.213 & 43.699 & 51.669 & 58.337 \\
\hline
\end{tabular}

Extraction Method: Principal Component Analysis.

Rotation Method: Varimax with Kaiser Normalization.

a. Rotation converged in 6 iterations.

Source: Survey Data (2018)

The Exploratory Factor Analysis (EFA) as tabulated in Table 4.9 was the stepping-stone for Confirmatory Factor Analysis (CFA). In CFA, the explicit model of the factor structure were constructed and the data were statistically tested its fit by underlying their observed pattern (Matsunaga, 2011)

\subsubsection{Confirmatory Factor Analysis}

In this study confirmatory factor analysis was used to analyze theoretical constructs through the loading of the measures, error, variances and covariance (Hopper, et al, 2008). The process involves reviewing the EFA in order to ensure that original variables were reflecting the latent variables by confirming and harmonizing the original variables are organized in the Confirmatory Factor Analys is (CFA).

\subsubsection{Measurement for Baseline Model}


In this study, in order to reach the baseline measurement model that fits both components, four individual measurement models were combined and CFA was run with maximum likelihood estimates in the Amos 22 to determine the fitness of the model. In order the model to fit well based on Hoe (2008) commonly applied fit indices require a model to achieve the following minimum requirements (CFI $>0.900$, GFI $>0.900$, AGFI $>0.800$ : Indicate good fit; RMSEA <.008: indicate Acceptable fit) and the ratio Chisquare to its degree of freedom $(\mathrm{CMIN} / \mathrm{DF}<3)$ to designate good fitness of the model. In order to improve the model some of the items that were affecting the significance of the model fitness were removed as proposed by Hooper, et al.(2008). Items with high covariance and high standardized regression weights (S.R.W) in the Modification Indeed (M.I) were removed in order to improve the model. The model was good fitted by meeting the above criteria whereby: Chi-square $=2.703 ; \mathrm{CFI}=0.925$, GFI $=0.932$, AGFI $=0.878$ : Indicate good fit; RMSEA $=0.047$ as per Figure 2.

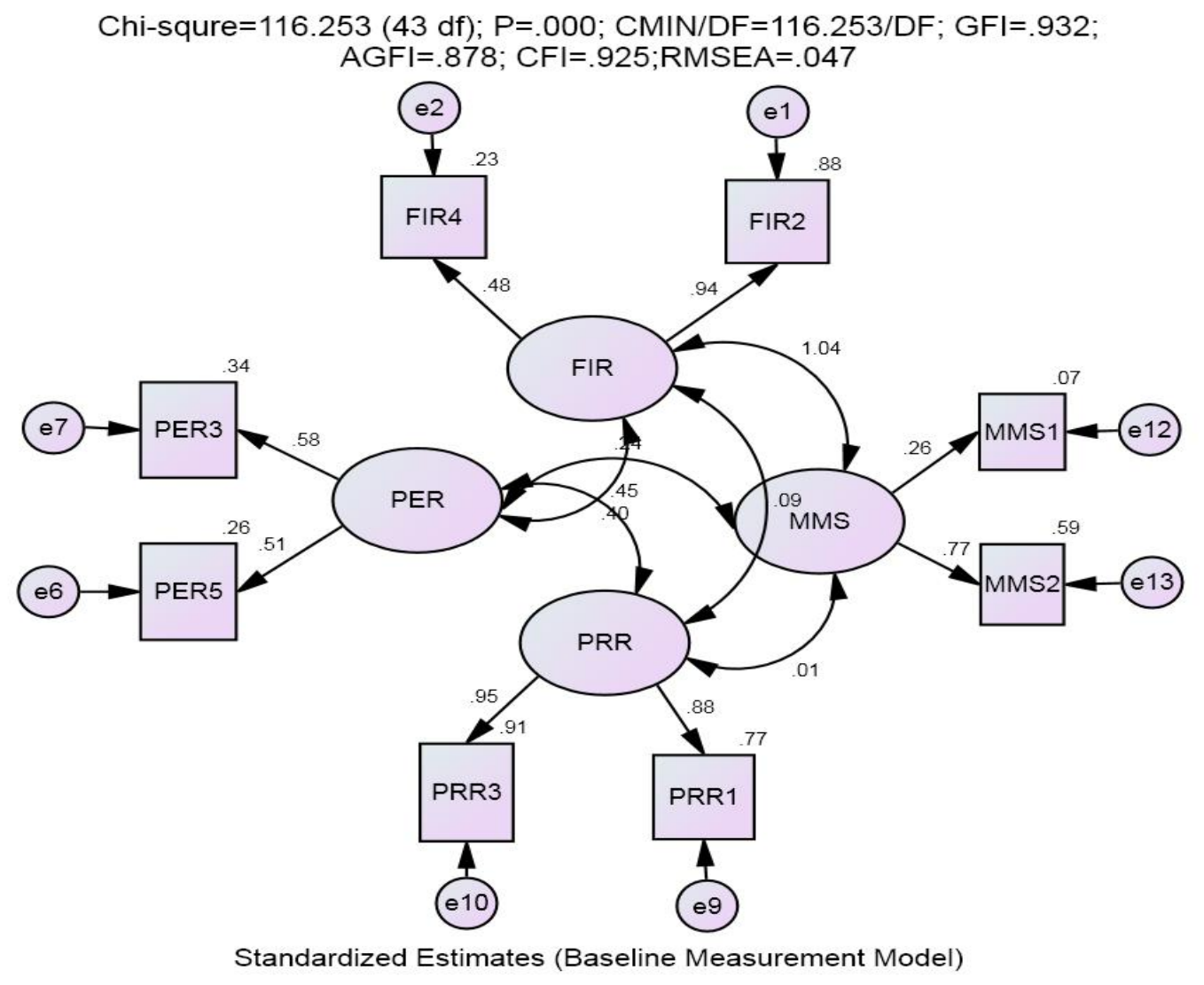

Key Note:

FIR: Financial Risk;FIR2: Theft and Fraud; FIR4: Alteration of Data;

PER: Performance Risk; PER3: Misallocation of Fund; PER5: Transactions Delay; PRR: Privacy Risk; PR4: Loss of Password;PR6: Information Hacking MMS: Mobile Money Services; MMS1: Money Transfer; MMS2: Prompt Payments

Fig.2: Baseline Measurement Model

Source: Survey Data (2018)

\subsubsection{Analysis of Structure Model}

The structure model hypothesized the relationship between perceived risk and mobile money services (MMS) usage by SMEs operations in Tanzania was analyzed. The structural model retrieved from IBM Amos version 22 had a standardized regression weight (SRW) more than 0.40 in the default model which indicated a good fit model and hence indicate adequate fit as per Figure 3. 


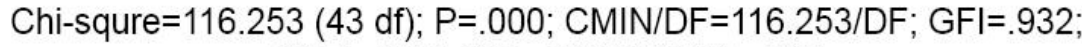

$\mathrm{AGFI}=.878 ; \mathrm{CFI}=.925 ; \mathrm{RMSEA}=.047$

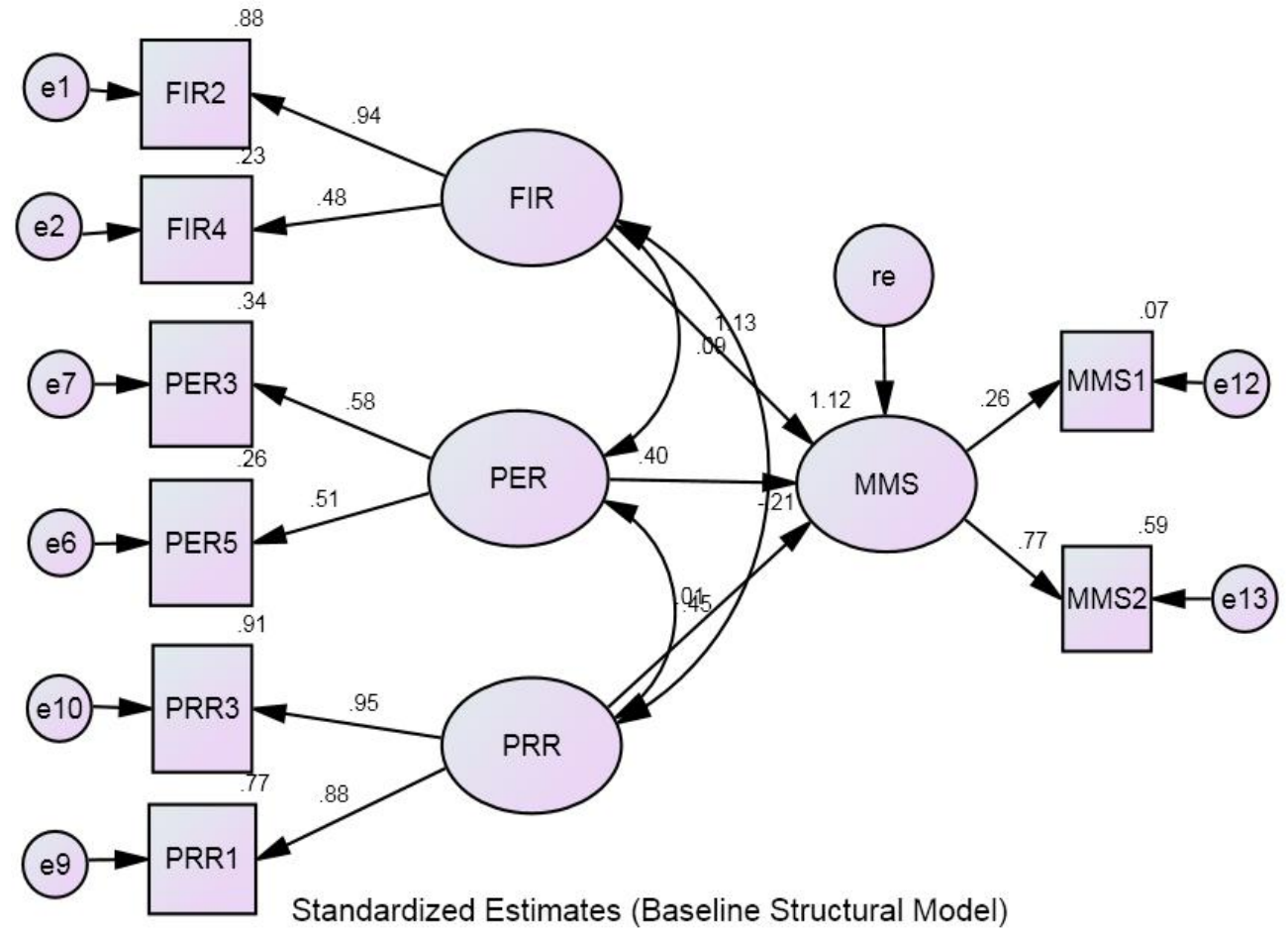

Key Note:

FIR: Financial Risk;FIR2: Theft and Fraud; FIR4: Alteration of Data; PER: Performance Risk; PER3: Misallocation of Fund; PER5: Transactions Delay; PRR: Privacy Risk; PR4: Loss of Password;PR6: Information Hacking MMS: Mobile Money Services; MMS1: Money Transfer; MMS2: Prompt Payments

Source: Survey Data (2018)

Fig.3: The Basic Structural Model

The finding in the model from analyzed data shows that, the ratio of chi- Square to the degree of freedom CMIN/DF which is commonly referred as the normal Chi- square value was 2.703 which falls in the range of is less than 3 as suggest to the fit model (Hooper, 2012). The fit indices yield the following results: $\mathrm{GFI}=0.932$, AGFI $=0.878, \mathrm{CFI}$ $=0.925$ obtained in the model falls in the accepted range of fitness of the model and hence indicate and excellent fitness of the model. Hoe (2008) suggested that a RMSEA value of 0.00 indicates perfect fit, the value ranging from 0.05 to 0.08 indicates acceptable fit, and 0.08 to 0.1 indicates ordinary fit while greater that 0.1 indicates poor fit. In this study, the RMSEA yield 0.047 which also fall on the accepted estimates to indicate a good fit of the model.

\subsection{Basic Model Path coefficients and Hypothesis Testing}

The hypothesized relationships are examined against various coefficients and scores obtained from the analysis. In this research the hypotheses are tested based on the direction, strength and the level of significance of the path coefficients. A standardized paths coefficient, critical ratio (C.R) and significant level (p-value) was used in this study to test and evaluate the strength and the level of significance of the hypotheses. Testing hypotheses at each run was done for comparison purposes.

\subsubsection{The influence of financial risk on mobile money services uptake}

The first postulated relationship in this study hypothesized a negative and strong significant relationship between financial risk and mobile money services usage by SMEs Operations in Tanzania as per hypothesis stated below:

H1: Financial risk (FIR) has negative and significant influence on Mobile money services (MMS) usage 
The analysis using Structure Equation Modeling (SEM) was done to determine the significance influence of financial risk on Mobile money services usage by SMEs Operations in Karagwe district as postulated in Table 3.

Table.3: Structural Model Regression Weights and Standardized Regression Weights on Financial Risk and mobile money services usage

\begin{tabular}{|cc|ccccc|c|l|}
\hline Path & Estimate & S.E. & C.R. & P & Label & $\begin{array}{c}\text { Standardized } \\
\text { Regression } \\
\text { Weights }\end{array}$ & Results \\
\hline MMS <--- & FIR & 0.580 & 0.120 & 5.635 & $* * *$ & par_2 & 0.328 & Accepted \\
FIR4 <--- & FIR & 1.000 & & & & & 0.475 & Accepted \\
FIR2 <--- & FIR & 1.662 & 0.198 & 8.400 & $* * *$ & par_7 & 0.938 & Accepted \\
\hline
\end{tabular}

Source: Survey Data (2018)

The path leading from PRR to MMS in Table 3 was used to examine the statistical relationship between financial risk and mobile money services usage by SMEs operation in Karagwe. In this study, the findings yield a critical ratio (C.R=5.635 which is greater than 1.96) and significance level of $\mathrm{p}=0.000$. This concurs with Hox and Bechger (2014) who argued that a relationship which yields a critical ratio more than 1.96 and p-value less than 0.05 is considered significant. This means that, the hypothesis $\mathrm{H}_{1}$ which states that, financial risk of has positive and significant influence on mobile money services usage is accepted.

\subsubsection{The influence of Performance Risk on Mobile}

Money Services uptake

The first postulated relationship in this study hypothesized a negative and strong significant relationship between performance risk and mobile money services usage by SMEs Operations in Tanzania as per hypothesis stated below:

H2: Performance risk (PER) has negative and significant influence on Mobile money services (MMS) usage

The analysis using Structure Equation Modeling (SEM) was done to determine the significance influence of performance risk on Mobile money services usage by SMEs Operations in Karagwe district as postulated in Table 4.

Table.4: Structural Model Regression Weights and Standardized Regression Weights on performance risk and mobile money services usage

\begin{tabular}{|c|c|c|c|c|c|c|c|}
\hline Path & Estimate & S.E. & C.R. & P & Label & $\begin{array}{c}\text { Standardized } \\
\text { Regression } \\
\text { Weights } \\
\end{array}$ & Results \\
\hline MMS <--- PER & 0.640 & 0.022 & 4.352 & *** & par_3 & 0.425 & Accepted \\
\hline PER5 <--- PER & 0.913 & 0.182 & 5.009 & $* * *$ & par_1 & 0.509 & Accepted \\
\hline PER3 <--- PER & 1.000 & & & & & 0.583 & Accepted \\
\hline
\end{tabular}

Source: Survey Data (2018)

The path leading from PRR to MMS in Table 4 was used to examine the statistical relationship between performance risk and mobile money services usage by SMEs operation in Karagwe district. In this study, the findings yield a critical ratio ( $C . R=4.352$ which is greater than 1.96) and significance level of $p=0.000$. This concurs with Hox and www.ijaems.com
Bechger (2014) who argued that a relationship which yields a critical ratio more than 1.96 and p-value less than 0.05 is considered significant. This means that, the hypothes is $\mathrm{H}_{2}$ which states that, financial risk of has positive and significant influence on mobile money services usage is accepted.

Page | 709 
5.2.3. The influence of Privacy Risk on Mobile Money Services uptake

The first postulated relationship in this study hypothesized a negative and strong significant relationship between privacy risk and mobile money services usage by SMEs Operations in Tanzania as per hypothesis stated below:
H3: Privacy risk (PRR) has negative and significant influence on Mobile money services (MMS) usage

The analys is using Structure Equation Modeling (SEM) was done to determine the significance influence of privacy risk on Mobile money services usage by SMEs Operations in Karagwe district as postulated in Table 5

Table.5: Structural Model Regression Weights and Standardized Regression Weights on privacy risk and mobile money services

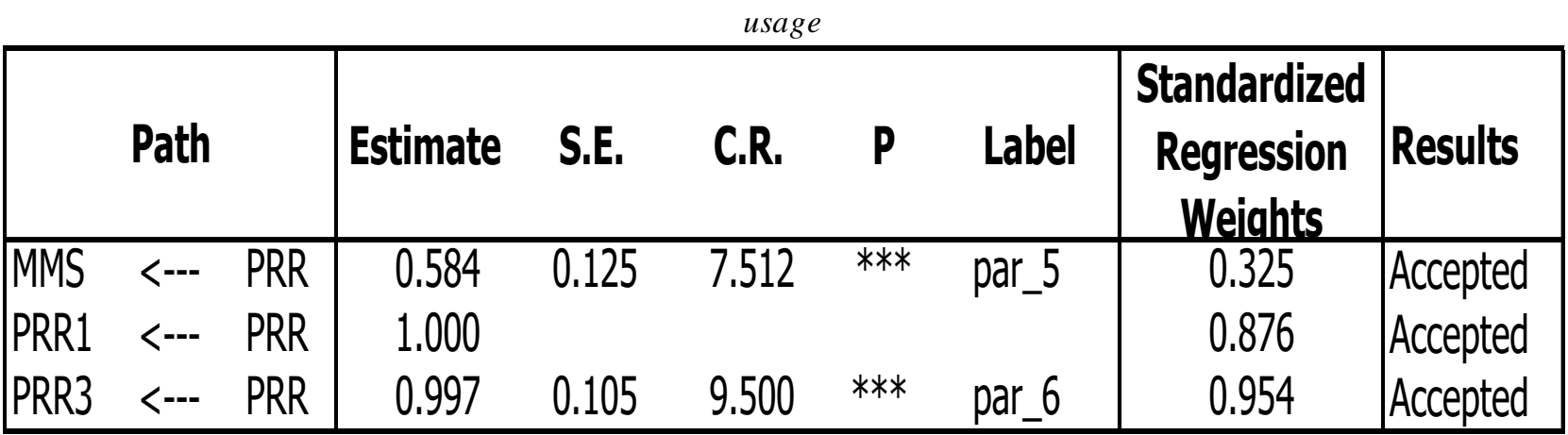

Source: Survey Data (2018)

The path leading from PRR to MMS in Table 5 was used to examine the statistical relationship between privacy risks with mobile money services usage by SMEs operation in Karagwe. In this study, the findings yield a critical ratio (C.R=7.512 which is greater than 1.96) and significance level of $\mathrm{p}=0.000$. This concurs with Hox and Bechger (2014) who argued that a relationship which yields a critical ratio more than 1.96 and $p$-value less than 0.05 is considered significant. This means that, the hypothesis $\mathrm{H}_{3}$ which states that, Privacy risk of has positive and significant influence on mobile money services usage is accepted. Hence this portray that, privacy risk contribute much in perceived risk associated with MMS in SMEs operation.

\section{CONCLUSION}

This part focus on major conclusions in line with study objectives

6.1. The influence of financial risk on mobile money services usage by SMEs Operations

The study assessed the relationship between financial risk and mobile money services usage by SMEs operations. The finding concluded that financial risk has negative and significant influence on the uptake of mobile money services by SMES in their business orientation. The study concluded that, there was a significant relationship between financial risk and mobile money services usage based on theft and fraud and alteration of data. Theft and fraud on mobile money services has great impact for SMEs operator on the ground that they will lose their wealth. Alteration of data on mobile money services has been reported by police and become cumbersome to call back the transactions which have been done without the as sent of account holder. This was found be strong reason on why SMEs operator are not encouraged to use mobile money services on their business undertaking. Obstinately to this, risk takers are using mobile money services which increase market share and assisted to link their business in the country and outside the country by taking the advantage of their geographical position.

6.2. The influence of performance risk on mobile money services usage by SMEs Operations

The study examined the relationship between performance risk and mobile money services usage by SMEs operations. Results indicated that, there were a negative and significant relationship between performance risk and mobile money services usage by SMEs runners. Performance risk is facilitated by misallocation of fund and transaction delay. It has shown that one performing financial transaction, it may happen to send the money for unintended person which call for misallocation of fund and in turn will cause loss in the business. In the same way, during network failure, there was delay in fund transfers which causes the delay to delivery of merchandise and slow down the business growth. In this context therefore, a risk averse will estate from using mobile money service in his business undertaking by fearing the performance risk. This leads to the conclusion that, mobile money services providers must ensure stable network and such that they reverse 
immediately the fund send to unintended personnel as they are assured for the wrong directed transaction.

\subsection{The influence of privacy risk on mobile money services usage by SME Operations}

The study examined the relationship between privacy risk and mobile money services usage by SMEs operations. Results indicated that, there were a negative and significant relationship between privacy risk and mobile money services usage by SMEs runners. The study concluded that, loss of password and information hacking were the key drivers in privacy risk. Loss of password lead not a user of mobile ,money service to perform financial transaction and hence require to visit the mobile money service provider to rest the password. According to geographical phenomena, the service of resetting the password is done by the agents who are found on the urban area hence need time and transportation cost for comprehending the task. In the same context, due to technological advancements, there are increasing the hacking of person information which leads to perform transaction without communicating to the mobile money account holder. The study concluded that, privacy risk has portion in increasing perceived risk and hence lead to a negative and significant influence on mobile money services usage by SMEs operation in Karagwe district.

\section{RECOMMENDATION}

The study recommended that, the government and other stakeholders has to make sure they instate esteemed infrastructure which will reduce network failure and hence ensure that perceived risk is mitigated. In the same vein, Policy and public interventions that emphasize both the skills and mobile infrastructure are important. Small enterprise should be facilitated through better policy interventions that enhance learning and knowledge sharing on opportunities offered by mobile money services and its impact on their business operations. Additionally, SMEs should be encouraged and assisted to embrace more mobile money usage behavior through proper policy guidelines. In this case, SMEs operator should strive to better understand the specific business activities they run and manage and thus align the mobile money resource acquisitions and deployment to meet and fit to their business operation.

While this study concentrated on the factors that influences perceived risk on mobile money services usage by SMEs operation in Karagwe, it is encouraged for other research to investigate other factors influencing mobile money services usage in the same study area or increase geographical area. Moreover, it is recommended to use Structural equation modeling in testing the hypothesis and hence determine the significant of each construct in the model.

\section{REFERENCES}

[1] Aldhmour, F. (2016). An Investigation of Factors Influencing Consumers' Intention to Use Online Shopping: An Empirical Study in South of Jordan. Journal of Internet Banking and Commerce, 21(2).

[2] Ali, K., Akhtar, M. F., \& Sadaqat, S. (2011). Financial and Non-Financial Business Risk Perspectives Empirical Evidence from Commercial Banks. Middle Eastern Finance and Economics, 11(11), 150-160.

[3] Bagana, M. S., \& Muturi, W. (2015). Factors Affecting the Uptake of Mobile Money Transfer Services by Small and Medium Enterprises in Pokot Central Sub County Abstract :, 3(4), 128-148.

[4] Baganzi, R., \& Lau, A. K. W. (2017). Examining trust and risk in mobile money acceptance in Uganda. Sustainability (Switzerland), 9(12).

[5] Buhalis, D. (2013). Ict As a New Competitive Advantage Factor - Case of Small Transitional, 15(1), 33-57.

[6] Featherman, M. S., \& Pavlou, P. A. (2003). Predicting e-services adoption: A perceived risk facets perspective. International Journal of Human Computer Studies, 59(4), 451-474.

[7] Gbongli, K., Peng, Y., \& Ackah, O. (2016). Selection and ranking of perceived risk associated with mobile banking in West Africa: An AHP Approach from customers' perspective. International Journal of Scientific \& Engineering Research, 7(1), 80-86.

[8] Gonzales, E. (2012). The Impact of Business Environment on Small and Medium Enterprise Sector , s Size and Employment: A Cross Country Comparison. Doing Business Research Conference.

[9] Hoe, S. L. (2008). Issues and procedures in adopting structural equation modeling technique. Journal of Applied Quantitative Methods, 3(1), 76-83.

[10] Hooper, D., Coughlan, J. and Mullen, M. R. (2008). Structural Equation Modeling: Guidelines for Determining Model Fit. The Electronic Journal of Business Research Methods. volume 6; number.1, pp. $53-60$

[11] Hox, J.J \& Bechger, T. . (2014). Introduction to Structural Equation Modeling. Family Science Review, 11(2), 354-373.

[12] Kallamarthodi, G., \& Vaithiyanathan, M. (2011). “ Empirical Assessment of a Modified Technology Acceptance Model in Emerging Economy: An Assessment from the Perspective of Indian Consumers 
", 25, 10-14.

[13] Kalugendo, J.E; Ndekwa, B., Ochumbo, A. J., \& Ndekwa, A. G. (2018). Adoption of Mobile Money Services among University Students in Tanzania. International Journal of Advanced Engineering, Management and Science (IJAEMS), 4(3), 149-157.

[14] Kolesova, I and Girzheva, Y. (2018). Impact of Financial Technologies on the Banking Sector. KnE Social Sciences, 3(2), 215. https://doi.org/10.18502/kss.v3i2.1545

[15] Lake, A. J. (2013). Risk management in Mobile Money : Observed Risks and Proposed Mitigants for Mobile Money Operators. International Finance Corporation, World Bank Group.

[16] Li, Z., \& Bai, X. (2010). Influences of perceived risk and system usability on the adoption of mobile banking service. International Symposium on Computer Science and Computational Technology, 51-54.

[17] Liu, Y., Yang, Y., \& Li, H. (2012). A Unified RiskBenefit Analysis Framework for Investigating Mobile Payment Adoption. International Conference on Mobile Business.

[18] Maditinos, D., Chatzoudes, D., \& Sarigiannidis, L. (2013). An examination of the critical factors affecting consumer acceptance of online banking: A focus on the dimensions of risk. Journal of Systems and Information Technology, 15(1), 97-116.

[19] Maziriri, E. T., \& Chuchu, T. (2017). The Conception of Consumer Perceived Risk towards Online Purchases of Apparel and an Idiosyncratic Scrutiny of Perceived Social Risk: A Review of Literature. International Review of Management and Marketing, 7(3), 257-265.

[20] Mohamad Radzi, K., Mohd Nor, M. N., \& Mohezar Ali, S. (2017). The Impact of Internal Factors on Small Business Success: A Case of Small Enterprises under the FELDA Scheme. Asian Academy of Management Journal, 22(1), 27-55.

[21] Mutalemwa, D.K \& Anthony, D. (2014). Factors influencing the Use of Mobile Payments in Tanzania : Insights from. The Journal of Language, Technology \& Entrepreneurship in Africa (JOLTE), Vol. 5 No. 2, 5(2), 69-90.

[22] Ngaruiya, B; Bosire, M; Kamau, S. . (2014). Effect of Mobile Money Transactions on Financial Performance of Small and Medium Enterprises in Nakuru Central Business District, 5(12), 53-59. 